\title{
Validation and Psychometric Properties of the German Version of the SWAL-QOL
}

Eva-Maria Kraus ${ }^{1}$, Natalie Rommel ${ }^{1,2}$ (MSc), Lisa H. Stoll ${ }^{1,2}$, Andreas Oettinger $^{3}$, Adam P. Vogel ${ }^{1,4, *,+}(\mathrm{PhD})$, Matthis Synofzik ${ }^{1,5, *,+}(\mathrm{MD})$

${ }^{1}$ Department of Neurodegeneration, Hertie Institute for Clinical Brain Research, University of Tübingen, Germany \& Center for Neurology, University Hospital Tübingen, Germany

${ }^{2}$ Therapiezentrum, University Hospital Tübingen, Germany

${ }^{3}$ Neurology and Rehabilitation, Kliniken Schmieder, Gailingen am Hochrhein, Germany

${ }^{4}$ Centre for Neuroscience of Speech, The University of Melbourne, Victoria, Australia

${ }^{5}$ Center for Neurodegenerative Diseases (DZNE), Tübingen, Germany

* joint last authors

${ }^{+}$Corresponding authors:

Dr. Matthis Synofzik

Center for Neurology

Hoppe-Seyler-Strasse 3

72076 Tübingen

Germany

Phone: +49 70712982060

Email: matthis.synofzik@uni-tuebingen.de

or

A/Prof Adam Vogel

Centre for Neuroscience of Speech

The University of Melbourne

550 Swanston Street, Parkville

Melbourne VIC 3010

Australia

Phone: +61 390355334 
Email: vogela@unimelb.edu.au

Word count abstract: 242 (max 250 words)

Word count main text: $\quad 3103$

References: $\quad 31$

Figures/Tables: 5 Tables

Supplementary files: $\quad 5$ Supplementary files

Running title: German SWAL-QOL: validation and psychometric properties

\section{Acknowledgments}

This study was supported by the IZKF Promotionskolleg Tübingen (to EK and MS, IZKF 2016-1-07), the National Health and Medical Research Council of Australia (Career Development Fellowship, ID 1082910, to APV) and the Alexander von Humboldt Foundation (to APV).

\section{Author contributions}

Ms Kraus contributed to the design of the study, collection, analysis and interpretation of the data, and drafting the manuscript.

Ms Rommel contributed to the design of the study, collection of the data, revising the manuscript for intellectual content and supervised students. Ms Stoll contributed to the design of the study, collection of the data, and revising the manuscript for intellectual content.

Mr Oettinger contributed to the design of the study, collection of the data, and revising the manuscript for intellectual content.

A/Prof Vogel conceptualized the study and contributed to the design of the study, analysis and interpretation of the data, and revising the manuscript for intellectual content. He also supervised students, led the research team, and obtained funding for the research.

Dr Synofzik conceptualized the study and contributed to the design of the study, collection, analysis and interpretation of the data, and revising the manuscript for intellectual content. He also supervised students, led the research team, and obtained funding for the research. 


\section{Compliance with Ethical Standards}

Financial Disclosures

Ms Kraus - None

Ms Rommel - None

Ms Stoll - None

Mr Oettinger - None

A/Prof Vogel receives funding from the National Health and Medical Research Council, Australia (Career Development Fellowship ID 1082910), is funded by Australian Research Council grants (LP130100026, DP130101900), receives funding from the Alexander von Humboldt Foundation and receives institutional support from The University of Melbourne.

Dr Synofzik received honoraria from Actelion pharmaceuticals, unrelated to the current study.

Informed consent and ethics approval

Informed written consent was obtained from all subjects. This study was approved by the ethics committee of the university of Tübingen (Az. 003/2015BO2 )

Keywords: dysphagia, deglutition, deglutition disorders, quality of life, translation, SWAL-QOL, Psychometric properties, SF-36 


\section{Abstract}

Background: The SWAL-QOL questionnaire is a common tool for evaluating patients' dysphagia-specific quality of life. A validated German version is not available. This study aimed to establish a German version of the SWAL-QOL (G-SWAL-QOL) using a standardized translation procedure, and to systematically evaluate its psychometric properties.

Methods: The original SWAL-QOL was translated into German following international translation guidelines. A pilot study (45 subjects) confirmed comprehensibility of the G-SWAL-QOL. A consecutive series of 158 subjects (103 patients with dysphagia; 55 healthy controls) was then recruited to assess validity and reliability of the G-SWAL-QOL. Construct validity was analyzed through a correlation analysis with both (i) the Anderson Dysphagia Inventory (ADI-D) and (ii) the Short-Form 36 (SF-36). Internal consistency and test-retest reliability were evaluated to determine reliability.

Results: All questions of the G-SWAL-QOL were comprehensible, except one which was subsequently revised. Construct validity of the G-SWAL-QOL was demonstrated by moderate to high correlations with the ADI-D (Spearman rho 0.36 - 0.88). The G-SWAL-QOL was able to differentiate between patients with dysphagia and healthy controls $(p<0.001)$, and was sensitive to disease severity measured by different food textures. Reliability of the G-SWAL-QOL was good to excellent for both internal consistency (Cronbach's $\alpha>0.7$ for all domains, except Eating Desire $[\alpha=0.69]$ ) and test-retest-reliability (Spearman's rho $\geq 0.68$ for all domains; ICC $>0.8$ for all domains).

Conclusion: The G-SWAL-QOL is a valid and reliable measuring tool for dysphagia-specific quality of life in German-speaking persons.

\section{Validation and Psychometric Properties of the German Version of the SWAL-QOL}

\section{Abstract}

Background: The SWAL-QOL questionnaire is a common tool for evaluating patients' dysphagia-specific quality of life. A validated German version is not 
available. This study aimed to establish a German version of the SWAL-QOL (G-SWAL-QOL) using a standardized translation procedure, and systematically evaluate its psychometric properties.

Methods: The original SWAL-QOL was translated into German following international translation guidelines. A pilot study (45 subjects) confirmed comprehensibility of the G-SWAL-QOL. A consecutive series of 158 subjects (103 patients with dysphagia; 55 healthy controls) was then recruited to assess validity and reliability of the G-SWAL-QOL. Construct validity was analyzed through a correlation analysis with both (i) the M.D. Anderson Dysphagia Inventory (MDADI-D) and (ii) the Short-Form 36 (SF-36). Internal consistency and test-retest reliability were evaluated to determine reliability.

Results: All questions of the G-SWAL-QOL were comprehensible, except one which was subsequently revised. Construct validity of the G-SWAL-QOL was demonstrated by moderate to high correlations with the MDADI-D (Spearman rho $0.35-0.90$ ). The G-SWAL-QOL was able to differentiate between patients with dysphagia and healthy controls $(p<0.001)$, and was sensitive to disease severity measured by different food textures. Reliability of the G-SWAL-QOL was good to excellent for both internal consistency (Cronbach's $\alpha>0.7$ for all domains, except Eating Desire $[\alpha=0.69]$ ) and test-retest-reliability (Spearman's rho $\geq 0.68$ for all domains; ICC $>0.8$ for all domains).

Conclusion: The G-SWAL-QOL is a valid and reliable measuring tool for dysphagia-specific quality of life in German-speaking persons. 


\section{Introduction}

Oropharyngeal dysphagia affects a broad variety of patients with neurological (e.g. Parkinson's Disease or stroke) or non-neurological (e.g. head and neck cancer) diseases [1]. While dysphagia increases the risk of malnutrition, dehydration, and aspiration, it also has an impact on social life and mental health, and thus, an individual's quality of life [2]. Impairment based swallowing assessments like Videofluoroscopic Swallowing Studies (VFSS) or Fibreoptic Endoscopic Evaluation of Swallowing (FEES) capture physiological deficits but fail to describe an individual's perception of severity or impact on quality of life. Adequate patient-based measures are, however, key outcome components of any meaningful clinical trial and rehabilitation strategy. In 2000, McHorney et al. developed the SWAL-QOL to provide a patient-based, dysphagia-specific quality of life outcome tool for evaluating patient outcomes and therapeutic efficacy [3]. Since then, the SWAL-QOL has become one of the most commonly used measures in dysphagia-related quality of life assessment and shows - in particular compared to most other available dysphagia self-report questionnaires - excellent reliability and convergent validity [4]. The questionnaire consists of 44 items grouped into a single symptom-frequency scale (Symptoms, 14 items) and ten further subscales: Burden, Eating Desire, Eating Duration, Food Selection, Communication, Fear of Eating, Mental Health, Social Functioning, Fatigue and Sleep, covering all WHO ICF (World Health Organization's International Classification of Functioning, Disability and Health) domains [4]. Additionally, the SWAL-QOL evaluates the dietary intake using three items. A final question records the patients' impression of their general health $[4,5]$. The SWAL-QOL has been translated into several languages including French [6], Dutch [7,8], Chinese [9], Swedish [10] and Italian [11].

A German translation has been published earlier, but the translation procedure did not follow a cross cultural adaptation process, nor did it confirm the validity or reliability of the translation $[12,13]$. The cross-cultural adaptation process of self-administered questionnaires is important to maintain the content validity at a conceptual level across different cultures [14]. Moreover, it is necessary to 
demonstrate the construct validity of the translated instrument. Construct validity defines how well the test measures up to its claims and is evaluated through convergent, discriminant and known-groups validity. Considering these different types of validity is a crucial step in questionnaire validation studies [15]. In the current study, we aimed to (i) develop a new cross-cultural adapted German SWAL-QOL version, and (ii) demonstrate its psychometric properties across patients experiencing dysphagia of different etiologies.

\section{Material and Methods}

\section{Cross-cultural adaptation process of the SWAL-QOL}

The original SWAL-QOL was translated into German according to the international translation guidelines of Beaton et al. [14] and Sousa and Rojjanasrirat [16]. Two German native speakers (one informed and one uninformed) independently translated the English version into German (stage 1: forward translation). Next, a third bilingual translator joined and both versions were combined into a consensus version, hereby building on the prior German translation of the SWAL-QOL [13,12] (stage 2: synthesis). This version was then retranslated by a bilingual person who was not familiar with the original questionnaire (stage 3: backward translation). An expert committee consisting of four translators, a language specialist and a person familiar with the methods of cross-cultural adaptation procedure was formed. The expert committee translated this new English version into German again, and examined it with regard to the following aspects: semantic, idiomatic, experiential and conceptual equivalence (stage 4: expert committee review). Finally, this preliminary German version was tested for comprehensibility of phrasing and language. For this purpose, a group of dysphagic patients ( $n=45$ subjects) was asked to rate every item on a 4-point Likert scale from "Fully comprehensible" to "Not at all comprehensible". If more than $20 \%$ of the patients (cut-off according to international translational guidelines [16]) marked an item as "Difficult to understand" or "Not at all comprehensible" the item was revised and tested again (stage 5: pretesting). Through these steps potential misunderstandings were eliminated and content validity was ensured. 
Subject cohorts and questionnaire assessments

All patients were recruited from the in-patient (neurology, oncology, and internal medicine) and out-patient clinics (ear-nose-throat [ENT], neurology) at the University Hospital, Tübingen, Germany, between January 2016 and November 2016. The inclusion criteria were: (i) oropharyngeal dysphagia diagnosed by a speech-language pathologist or an ENT specialist by means of VFSS or FEES and (ii) constant level of dysphagia over $\geq 4$ weeks according to the patients' anamnesis and case history. The exclusion criteria were: (i) inability to read or write fluent German, (ii) purely esophageal dysphagia, or (iii) cognitive impairment as screened by the Montreal Cognitive Assessment (MOCA $\leq 21$ points) [17]. Healthy control subjects were recruited from the general community and via relatives of the index patients. All control subjects did not present with any signs of dysphagia or cognitive deficits (MOCA $>27$ points). Based on these inclusion and exclusion criteria, 103 patients and 55 healthy controls were included in the validation study. This study was approved by the ethics committee of the University of Tübingen (Az. 003/2015BO2).

The subjects completed three questionnaires: (i) the German version of the SWAL-QOL (G-SWAL-QOL), (ii) the German Version of the M.D. Anderson Dysphagia Inventory (MDADI-D) [18], and (iii) the German version of the Short Form-36 (SF-36) [19], in exactly this order. Any help required in completing the questionnaires was documented. Participation took between 20 and 35 minutes for patients that completed the questionnaires on their own and between 25 and 70 minutes for those who required assistance. To determine test-retest reliability of the G-SWAL-QOL, 20 out of the 103 patients were recruited on an opportunity basis. The first 20 subjects that agreed to complete the G-SWAL$\mathrm{QOL}$ for a second time were included. They were asked to complete the second G-SWAL-QOL by mail after an average of two weeks.

The items of the G-SWAL-QOL are constructed as a 1 to 5 -point Likert scale. Each subscale was linearly transformed so that possible scores range from 0 to 100 , with 100 indicating high dysphagia-specific quality of life $[5,20]$. According to the authors of the original SWAL-QOL, the Symptoms scale evaluating the severity of pharyngeal, saliva and oral symptoms provides useful information for 
clinical researchers, but should be considered separately [5]. Hence, the GSWAL-QOL total score was calculated from the remaining ten subscales and consists of 30 items.

\section{Validity}

Construct validity was assessed by determining convergent, discriminant and known-groups validity. Convergent validity can be assumed if there is a correlation between two measures of the same underlying construct, whereas discriminant validity refers to the absence of correlation between measures of unrelated constructs [15]. To evaluate convergent and discriminant validity, the G-SWAL-QOL was correlated to a dysphagia handicap self-report instrument, namely the MDADI-D [18], and a global, non-dysphagia related quality of life instrument, the German version of the SF-36 [19]. The M.D. Anderson Dysphagia Inventory is a patient-completed outcome tool designed to assess the psychosocial aspects of dysphagia, comprising of 20 items grouped into four sections: Global, Emotional, Functional and Physical. The Global section includes only one item and is scored individually. The other sections are summed and a total score is calculated ranging from 0 (low functioning) to 100 (high functioning) [21]. The SF-36 is a 36-item-scale which assesses eight health concepts: Physical Functioning, Bodily Pain, Role Limitations due to Physical Problems, Role Limitations due to Emotional Problems, General Health, Vitality, Social Functioning and Mental Health. A generalized scoring system for each domain produces a score from 0 to 100, with 100 indicating maximal health-related quality of life. Additionally, the summary measures for physical and mental health known as the Physical Health Component Score (PCS) and the Mental Health Component Score (MCS) were derived based on German population norms [22,23].

For these correlations, which were calculated using Spearman's rho correlation coefficient $\left(r_{s}\right)$, at least 75 subjects would be required to achieve a statistical power of 0.95 to detect a population $r$ of 0.4 (i.e., the effect size chosen here) at $\alpha=0.05$ [24]. The effect size of 0.4 was based on the results for the construct validity of the original SWAL-QOL [5]. Spearman's rho values $>0.7$ suggest a 
strong correlation, values between 0.3 and 0.7 a moderate correlation, and values $<0.3$ a weak correlation $[15,25]$.

To analyze the factor structure of the subscales of the G-SWAL-QOL, a principal component analysis (PCA) was performed. First, Bartlett's Test of Sphericity and the Kaiser-Meyer-Olkin Measure of Sampling Adequacy (KMO) were used to test the suitability of our data for a PCA [26]. As our data were suitable, the Kaiser criterion and the scree-plot were used to determine the number of underlying factors [15]. Finally, to facilitate interpretation, orthogonal and oblique rotation were performed. As some correlations exceeded 0.32 in the factor correlation matrix, oblique rotation is recommended and, thus, was primarily considered $[15,27]$.

Construct validity was further tested using the known-groups validity. Here the questionnaire is administered to two groups which logically have different levels of the construct to confirm whether the hypothesized difference is reflected in the scores of the two groups [15]. To determine the known-groups validity, the G-SWAL-QOL scores for healthy controls and patients with dysphagia were compared using the Mann-Whitney-U-Test. The G-SWAL-QOL scores of the dysphagic patient group stratified according to their capacity to swallow different food textures (unmodified diet vs soft and pureed diets; unmodified diet vs tubefed patients and soft and pureed diet vs tube-fed patients) were compared using Kruskal-Wallis-Test. When the Kruskal-Wallis-Test yielded a significant effect $(p<0.05)$, post-hoc analysis was performed using a Dunn-Bonferroni-Test. The effect size was interpreted according to Cohen [24], with $r=0.1$ reflecting a small effect size, $r=0.3$ a medium effect size and $r=0.5$ a large effect size [28].

\section{Reliability}

Internal consistency of the G-SWAL-QOL was assessed using Cronbach's $\alpha$. Cronbach's $\alpha$ values $\geq 0.7$ are indicative of good internal consistency and satisfactory for group-level research, while values $\geq 0.8$ are recommended for individual patient decision-taking [29]. Short term stability of the G-SWAL-QOL was determined calculating its test-retest reliability. For these calculations Spearman's rho correlation coefficient and intraclass correlations (two-way mixes-effects model for agreement, $\operatorname{ICC}(3, \mathrm{k}))$ were used [30]. 


\section{Score distribution}

The distribution of score values of the G-SWAL-QOL and the presence of floor and ceiling effects was analyzed. Floor and ceiling effects occur if more than $15 \%$ of the respondents achieved the lowest or highest possible score which would indicate low discrimination of the respective scale [31].

Statistical Analysis

Statistical analysis was performed using SPSS 23 (IBM, SPSS, Inc., Chicago, IL, USA). Non-parametric tests were used as data were not normally distributed. The correlation analyses of the SWAL-QOL and MDADI-D/SF-36 subscales were Bonferroni-corrected for multiple comparisons.

\section{Results}

Comprehensibility testing of the G-SWAL-QOL

Out of 44 items of the G-SWAL-QOL, only item \#29 (original wording: "I never know when I am going to choke") showed poor comprehensibility, i.e. was marked as "Difficult to understand" or "Not at all comprehensible" by $22.2 \%$ of the 45 subjects tested. A modified translation of item \#29 was subsequently produced by the translation team, and tested in 22 additional dysphagic patients. Of these 22 subjects, 18 considered this newly translated item comprehensible (81.8\%), four marked it as "Difficult to understand" (18.2\%), but notably no subjects marked it as "Not at all comprehensible" (for subject characteristics of the comprehensibility testing group, see Supplementary Material 1).

Subject cohort characteristics and feasibility of the G-SWAL-QOL

Of 116 patients who completed the G-SWAL-QOL, 13 subjects left more than $10 \%$ of the G-SWAL-QOL blank; their results were excluded from further analysis. Thirty three percent (9/27) of the tube-fed patients compared to $4 / 89$ $(4.5 \%)$ of the patients with oral intake did not complete the questionnaire $(p<0.001)$. Causes of dysphagia in the subject cohort included head and neck cancer (31.1\%), stroke (10.7\%), Parkinson's disease (13.6\%), other neurodegenerative disease (23.3\%) and other neurologic or non-neurological 
diseases $(21.4 \%$ [e.g. multiple sclerosis, brain tumor, muscular dystrophy, systemic scleroderma]). Completion of the questionnaire took on average 14 minutes; none of the subjects needed more than 25 minutes. Patients and healthy controls did not differ in age and gender (for further subject characteristics, dysphagia severity, etc., see Table 1).

\section{Convergent and discriminant validity}

MDADI-D. Eight of eleven subscales of the G-SWAL-QOL focusing on directly dysphagia-related QOL items and the G-SWAL-QOL total score showed significant moderate $\left(r_{s} 0.36-0.70\right)$ or strong correlations $\left(r_{s} 0.72-0.90\right)$ with all sections of the MDADI-D. No significant correlations were found between the Communication subscale, the Fatigue subscale, the Sleep subscale of the GSWAL-QOL and most of the MDADI-D sections: The Fatigue subscale revealed moderate correlations with (i) the MDADI-D Global section $\left(r_{s}=0.44\right)$ and (ii) the MDADI-D Emotional section $\left(r_{s}=0.36\right)$. The Sleep subscale revealed a moderate correlation $\left(r_{s}=0.35\right)$ with the MDADI-D Global section. The Communication subscale was not correlated with the MDADI-D (see Table 2). Notably, all three G-SWAL-QOL scales did not measure direct dysphagiarelated $\mathrm{QOL}$ items.

SF-36. The G-SWAL-QOL subscales Mental Health, Social Functioning, Fatigue and Sleep showed significant correlations with various SF-36 domains: G-SWAL-QOL Mental Health with SF-36 Vitality $\left(r_{s}=0.41\right)$ and SF-36 Mental Health $\left(r_{s}=0.37\right)$; G-SWAL-QOL Social Functioning with SF-36 Vitality $\left(r_{s}=0.35\right)$, SF-36 Social Functioning $\left(r_{s}=0.43\right)$ and SF36 Mental Health $\left(r_{s}=0.37\right)$; G-SWAL-QOL Fatigue with SF-36 Physical Functioning $\left(r_{s}=0.37\right)$, SF-36 Role Physical $\left(r_{s}=0.36\right)$, SF-36 General Health $\left(r_{s}=0.37\right)$, SF-36 Vitality $\left(r_{s}=0.63\right)$, SF-36 Social Functioning $\left(r_{s}=0.45\right)$, and SF-36 Mental Health $\left(r_{s}=0.41\right)$; G-SWAL-QOL Sleep with SF-36 Vitality $\left(r_{s}=0.38\right)$, SF-36 Social Functioning $\left(r_{s}=0.34\right)$, and SF-36 Mental Health $\left(r_{s}=0.44\right)$. Three further significant correlations were found for: (i) G-SWAL-QOL Burden with SF-36 Bodily Pain $\left(r_{s}=0.38\right)$, (ii) G-SWAL-QOL Food Selection with SF-36 Vitality $\left(r_{s}=0.36\right)$ and (iii) G-SWAL-QOL Fear of Eating with SF-36 Vitality $\left(r_{s}=0.39\right)$ (see Table 3). No significant correlations were found between the Eating Desire 
subscale, the Eating Duration subscale, the Communication subscale, the Symptoms scale of the G-SWAL-QOL and any of the SF-36 domains (see Table 3).

These results largely correspond with the results observed in a correlation analysis between the G-SWAL-QOL and the composite SF-36 Mental Health and Physical Health Component Scores (see Supplementary Material 2).

In sum, the dysphagia-specific subscales of the G-SWAL-QOL primarily correlated with the MDADI-D, whereas the generic subscales of the G-SWALQOL primarily correlated with the SF-36. This indicates that the G-SWAL-QOL captures different, at least partly independent factors, whereby the MDADI captures more dysphagia-related items.

This notion is corroborated by our principal component analysis (PCA), which extracted three definite, at least partly independent factors of the G-SWALQOL: (i) dysphagia-specific QOL (Food Selection, Eating Desire, Burden, Social Functioning, Eating Duration, Mental Health), (ii) generic QOL (Sleep and Fatigue) and (iii) communication-related QOL (Communication) (results of the pattern matrix after oblique rotation [oblimin direct], see Supplementary Material 3).

\section{Known-groups validity}

The patient group yielded significantly lower scores in the G-SWAL-QOL than the healthy control group $(p<0.000001)$. The mean difference ranged from 54 points (Eating Duration) to 25 points (Sleep). The effect size was large for all subscales $(0.57-0.80)$ except the Sleep subscale $(0.40)$ (see Table 4$)$. Both patients who were on a soft/pureed diet and patients who were tube-fed yielded significantly lower scores in most of the G-SWAL-QOL subscales than patients on an unmodified diet (for more detailed results see Supplementary Material 4). This indicates that the G-SWAL-QOL also differentiates within the dysphagia patient group as stratified according to food texture intake.

Like the G-SWAL-QOL, the MDADI-D was able to differentiate within the dysphagia patient group as stratified according to food texture intake, whereas the SF-36 did not differentiate (see Supplementary Material 5). This again 
supports the notion that the MDADI-D captures dysphagia-related behaviors more closely than the SF-36.

Reliability

For internal consistency the total G-SWAL-QOL as well as all subscales reached the widely accepted [29] Cronbach's $\alpha$ of $\geq 0.7(0.71-0.93)$ except the Eating Desire subscale which reached the cut-off at borderline $(\alpha=0.69)$. Five subscales (Symptoms, Fatigue, Mental Health, Burden and Social Functioning) and the total G-SWAL-QOL reached the recommended $\alpha$ of $\geq 0.8(0.80-0.94)$ [29]. For test-retest reliability, Spearman's rho values ranged from 0.68 (Fatigue) to 0.95 (Eating Duration), ICC values ranged from 0.81 (Sleep) to 0.98 (Eating Duration) (for overview, see Table 5).

Score distribution

Scores ranged from the lowest possible score $(0)$ to the highest possible score (100) in the dysphagic patient group for most of the subscales. Only the GSWAL-QOL total score (range 8 -95), the Symptoms scale (range $14-89$ ) and the Eating Desire subscale (range 8 - 100) did not reach the maximal range. The mean scores ranged from 43.2 (Eating Duration) to 68.7 (Food Selection). Floor effects were observed for only one scale (Eating Duration); ceiling effects for three scales (Eating Desire, Food Selection and Social Functioning) (see Table 6). 


\section{Discussion}

Validated scales capturing an individual's' perception of dysphagia severity and dysphagia-related quality of life are an essential instrument not only for guiding individual dysphagia treatment, but also as outcome measures for clinical trials in dysphagia. The SWAL-QOL provides such an instrument [3], however, a cross-cultural adapted and validated German version has not yet been published. This impedes valid use of the SWAL-QOL in clinical practice for German-speaking dysphagic patients, as well as use of this instrument in clinical trials in German-speaking populations. Here we provide a cross-cultural adapted German translation of the SWAL-QOL and demonstrate its validity and reliability.

\section{Comprehensibility of the G-SWAL-QOL}

Almost all items of the preliminary G-SWAL-QOL version showed good comprehensibility. Only item \#29 needed a re-translation, which yielded only a small improvement in comprehensibility. Corresponding to the limited comprehensibility, the Fear of Eating subscale of the SWAL-QOL received relatively low internal consistency results in the original English version $(\alpha=0.79$ [5]), in a Dutch translation $(\alpha=0.79$ [7]) and in our translation $(\alpha=0.78$ ), which can be improved by omitting item \#29 (to $\alpha=0.80$ in the Dutch version, and to $\alpha=0.81$ in our version). Future studies may consider whether this small gain in a justifies omitting this item from the SWAL-QOL in future versions.

\section{Validity of the G-SWAL-QOL}

Content validity refers to the extent to which a specific collection of items reflects a content domain [15]. McHorney et al. established content validity for the original SWAL-QOL $[3,20]$. As we used the cross-cultural adaptation procedure following respective international guidelines [14,16], a similar content validity for the G-SWAL-QOL can be assumed.

The dysphagia-specific subscales of the G-SWAL-QOL showed excellent correlations with the MDADI-D demonstrating its convergent validity. The GSWAL-QOL subscales Mental Health, Social Functioning, Fatigue and Sleep 
showed significant correlations with SF-36 domains and the SF-36 Mental Health Component Score, which capture the same construct, just in a more general manner. Taken together, these findings demonstrate convergent validity of the G-SWAL-QOL with both the MDADI-D and the SF-36 in the respective constructs.

In contrast, the subscales Eating Desire, Eating Duration, Communication and the Symptoms scale of the G-SWAL-QOL did not correlate with the SF-36 domains. This lack of correlation can be explained by the fact that these more symptom-specific subscales of the G-SWAL-QOL test different constructs than the generic global health-related QOL measures of the SF-36 [32], supporting the discriminant validity of the G-SWAL-QOL.

The G-SWAL-QOL differentiated between dysphagic patients and healthy controls as well as within groups according to dysphagia impairment (dysphagic patients with food texture limitations vs dysphagic patients without limitations) demonstrating that the German version also has known-groups validity.

Reliability of the G-SWAL-QOL

The G-SWAL-QOL shows good internal consistency and excellent short-term stability. Only the Eating Desire subscale $(\alpha=0.69)$ yielded Cronbach $\alpha$ values for internal consistency at borderline of the accepted cut-off $(\alpha \geq 0.70)$. This is, however, higher than the internal consistency values for this subscale observed in the Dutch $(\alpha=0.67 ;[8])$ and Chinese $(\alpha=0.48$; [9]) versions of the SWALQOL.

Score distribution of the G-SWAL-QOL

The responses of the dysphagic patient group reached the full range of possible scores for most of the subscales. All of the floor and ceiling effects observed were also reported for the original SWAL-QOL [5]. Following interpretation by the authors of the original SWAL-QOL, these observed floor and ceiling effects might be of minor relevance for the overall SWAL-QOL scores in studies of dysphagia progression or treatment effectiveness, as subjects might still improve or decline in all other SWAL-QOL subscales [5]. 


\section{Limitations of the SWAL-QOL}

Some items of the SWAL-QOL only address oral feeders and are difficult to answer for patients on tube feeding. McHorney et al. [5] and Finizia et al. [10] discuss that tube-fed patients often described difficulties answering questions because they did not consider the questions to be relevant for their situation (e.g. one patient wrote: "You should word your questions so that people like myself who live with a $G$ tube can answer a little better.") [5,10]. In line with these previous reports (see also [33]), our observations suggest that patients receiving tube-feeding without oral intake had significantly higher levels of missing items. Hence, results concerning this patient group should be interpreted with caution. Additional modules for patients without oral intake, as suggested by McHorney et al. [5], might help to address this problem in the future. 


\section{References}

1. Malagelada J-R, Bazzoli F, Boeckxstaens G, De Looze D, Fried M, Kahrilas P, Lindberg G, Malfertheiner P, Salis G, Sharma P (2015) World Gastroenterology Organisation Global Guidelines: Dysphagia-Global Guidelines and Cascades Update September 2014. Journal of clinical gastroenterology 49 (5):370-378

2. Ekberg O, Hamdy S, Woisard V, Wuttge-Hannig A, Ortega P (2002) Social and psychological burden of dysphagia: its impact on diagnosis and treatment. Dysphagia 17 (2):139-146 3. McHorney CA, Bricker DE, Kramer AE, Rosenbek JC, Robbins J, Chignell KA, Logemann JA, Clarke C (2000) The SWAL-QOL outcomes tool for oropharyngeal dysphagia in adults: I. Conceptual foundation and item development. Dysphagia 15 (3):115-121

4. Keage M, Delatycki M, Corben L, Vogel A (2015) A systematic review of self-reported swallowing assessments in progressive neurological disorders. Dysphagia 30 (1):27-46 5. McHorney CA, Robbins J, Lomax K, Rosenbek JC, Chignell K, Kramer AE, Bricker DE (2002) The SWAL-QOL and SWAL-CARE outcomes tool for oropharyngeal dysphagia in adults: III. Documentation of reliability and validity. Dysphagia 17 (2):97-114

6. Khaldoun E, Woisard V, Verin E (2009) Validation in French of the SWAL-QOL scale in patients with oropharyngeal dysphagia. Gastroentérologie clinique et biologique 33 (3):167171

7. Vanderwegen J, Van Nuffelen G, De Bodt M (2013) The validation and psychometric properties of the Dutch version of the Swallowing Quality-of-Life Questionnaire (DSWAL-QOL). Dysphagia 28 (1):11-23

8. Bogaardt H, Speyer R, Baijens L, Fokkens W (2009) Cross-cultural adaptation and validation of the Dutch version of SWAL-QoL. Dysphagia 24 (1):66-70

9. Lam PM, Lai CKY (2011) The validation of the Chinese version of the Swallow Quality-of-Life Questionnaire (SWAL-QOL) using exploratory and confirmatory factor analysis. Dysphagia 26

(2):117-124

10. Finizia C, Rudberg I, Bergqvist $H$, Rydén A (2012) A cross-sectional validation study of the Swedish version of SWAL-QOL. Dysphagia 27 (3):325-335

11. Ginocchio D, Alfonsi E, Mozzanica F, Accornero AR, Bergonzoni A, Chiarello G, De Luca N, Farneti D, Marilia S, Calcagno P (2016) Cross-Cultural Adaptation and Validation of the Italian Version of SWAL-QOL. Dysphagia:1-9

12. Stanschuss $S$ (2006) Rehabilitation von Dysphagien. Schulz-Kirchner Verlag GmbH, Idstein 13. Flieger F, Alpermann A (2012) Untersuchung der Verständlichkeit der deutschen Übersetzung des Fragebogens SWAL-QoL (Swallowing Quality of Life). DYSPHAGIE FORUM 2 (1):2-15. doi:10.2443/skv-s-2012-55020120101

14. Beaton DE, Bombardier C, Guillemin F, Ferraz MB (2000) Guidelines for the process of cross-cultural adaptation of self-report measures. Spine 25 (24):3186-3191

15. DeVellis RF (2012) Scale development: theory and applications. 3rd edn. Sage publications, Los Angeles

16. Sousa VD, Rojjanasrirat W (2011) Translation, adaptation and validation of instruments or scales for use in cross-cultural health care research: a clear and user-friendly guideline. Journal of evaluation in clinical practice 17 (2):268-274

17. Nasreddine ZS, Phillips NA, Bédirian V, Charbonneau S, Whitehead V, Collin I, Cummings JL, Chertkow H (2005) The Montreal Cognitive Assessment, MoCA: a brief screening tool for mild cognitive impairment. Journal of the American Geriatrics Society 53 (4):695-699

18. Bauer F, Seiss M, Grässel E, Stelzle F, Klotz M, Rosanowski F (2010) [Swallowing-related quality of life in oral cavity cancer. The German version of the Anderson Dysphagia Inventory]. Hno 58 (7):692-697 
19. Bullinger M, Kirchberger I, Ware J (1995) Der deutsche SF-36 Health Survey Übersetzung und psychometrische Testung eines krankheitsübergreifenden Instruments zur Erfassung der gesundheitsbezogenen Lebensqualität. Zeitschrift für Gesundheitswissenschaften= Journal of public health 3 (1):21-36

20. McHorney CA, Bricker DE, Robbins J, Kramer AE, Rosenbek JC, Chignell KA (2000) The SWAL-QOL outcomes tool for oropharyngeal dysphagiain adults: II. item reduction and preliminary scaling. Dysphagia 15 (3):122-133

21. Chen AY, Frankowski R, Bishop-Leone J, Hebert T, Leyk S, Lewin J, Goepfert H (2001) The development and validation of a dysphagia-specific quality-of-life questionnaire for patients with head and neck cancer: the MD Anderson dysphagia inventory. Archives of Otolaryngology-Head \& Neck Surgery 127 (7):870-876

22. Bullinger M, Kirchberger I (1998) Der SF-36 Fragebogen zum Gesundheitszustand.(SF-36)Handbuch für die deutschsprachige Fragebogenversion. Hogrefe, Göttingen 23. Ellert U, Kurth B-M (2004) Methodische Betrachtungen zu den Summenscores des SF-36 anhand der erwachsenen bundesdeutschen Bevölkerung. BundesgesundheitsblattGesundheitsforschung-Gesundheitsschutz 47 (11):1027-1032

24. Cohen J (1988) Statistical power analysis for the behavior science. 2nd edn. Lawrance Eribaum Association, Hillsdale, New Jersey

25. McDowell I (2006) Measuring health: a guide to rating scales and questionnaires. 3rd edn. Oxford university press, New York

26. Dziuban CD, Shirkey EC (1974) When is a correlation matrix appropriate for factor analysis? Some decision rules. Psychological bulletin 81 (6):358

27. Tabachnick B, Fidell L (2007) Using Multivariate Statistics., 5th edn.(Pearson: Boston, MA.). 646

28. Field A (2014) Discovering statistics using SPSS. 4th edn. Sage publications, Los Angeles 29. Nunally J, Bernstein I (1994) Psychometric theory. McGraw-Hill, New York

30. Portney L, Watkins M (1993) Foundations of Clinical Research. Applications and Practice Norwalk, Connecticut: Appleton \& Lange. Journal of Rehabilitation 74 (3)

31. McHorney CA, Tarlov AR (1995) Individual-patient monitoring in clinical practice: are available health status surveys adequate? Quality of Life Research 4 (4):293-307

32. Wilson IB, Cleary PD (1995) Linking clinical variables with health-related quality of life: a conceptual model of patient outcomes. Jama 273 (1):59-65

33. Rinkel RN, Verdonck-de Leeuw IM, Langendijk JA, van Reij EJ, Aaronson NK, Leemans CR (2009) The psychometric and clinical validity of the SWAL-QOL questionnaire in evaluating swallowing problems experienced by patients with oral and oropharyngeal cancer. Oral oncology 45 (8):e67-e71

Table 1 Characteristics and group differences between dysphagic and control subjects

\begin{tabular}{|l|l|l|l|l|}
\hline Characteristic & Study group $(n=103)$ & Control group $(n=55)$ & $\begin{array}{l}\text { Sig. two } \\
\text { tailed }\end{array}$ \\
\hline Age (years) & $60.0(15.5)$ & & $61.3(9.9)$ & \\
\hline mean (SD) & $\begin{array}{l}\text { U-Test: } \\
p=0.943\end{array}$ \\
\hline
\end{tabular}




\begin{tabular}{|c|c|c|c|c|c|}
\hline median & 62 & & 61 & & \\
\hline \multirow[t]{2}{*}{ range } & $21-89$ & & $22-83$ & & \\
\hline & number & $\%$ & number & $\%$ & \\
\hline \multicolumn{6}{|l|}{ Gender } \\
\hline Male & 60 & 58.3 & 31 & 56.4 & \multirow{2}{*}{$\begin{array}{l}x^{2}: \\
p=0.819\end{array}$} \\
\hline Female & 43 & 41.7 & 24 & 43.6 & \\
\hline \multicolumn{6}{|l|}{ Etiology } \\
\hline head and neck cancer & 32 & 31.1 & & & \\
\hline vascular disease (stroke) & 11 & 10.7 & & & \\
\hline Parkinson's Disease & 14 & 13.6 & & & \\
\hline other neurodegenerative diseases & 24 & 23.3 & & & \\
\hline other neurologic diseases & 14 & 13.6 & & & \\
\hline other non-neurological dysphagia & 8 & 7.8 & & & \\
\hline \multicolumn{6}{|c|}{ Degree of severity as determined by the BODS summation score [1] } \\
\hline Mild Dysphagia (BODS $3-4$ ) & 50 & 48.5 & & & \\
\hline Moderate Dysphagia (BODS 5 - 9) & 30 & 29.1 & & & \\
\hline Severe Dysphagia (BODS $10-16$ ) & 23 & 22.3 & & & \\
\hline \multicolumn{6}{|l|}{ Texture of current eating behavior } \\
\hline full/ normal oral & 56 & 54.4 & 55 & 100 & \\
\hline soft & 19 & 18.4 & 0 & 0 & \\
\hline pureed & 10 & 9.7 & 0 & 0 & \\
\hline $\begin{array}{l}\text { pleasure (mainly tube but sometimes } \\
\text { ice cream/pudding etc) }\end{array}$ & 8 & 7.8 & 0 & 0 & \\
\hline full non-oral (tube) & 10 & 9.7 & 0 & 0 & \\
\hline \multicolumn{6}{|l|}{ Texture of current drinking behavior } \\
\hline normal & 91 & 88.3 & 55 & 100 & \\
\hline thickened & 2 & 1.9 & 0 & 0 & \\
\hline full non-oral (tube) & 10 & 9.7 & 0 & 0 & \\
\hline \multicolumn{6}{|l|}{ Place of living } \\
\hline home & 92 & 89.3 & 55 & 100 & \multirow{2}{*}{$\begin{array}{l}x^{2}: \\
p=0.012\end{array}$} \\
\hline residential care & 11 & 10.7 & 0 & 0 & \\
\hline \multicolumn{6}{|l|}{ Smoker } \\
\hline no & 69 & 67.0 & 45 & 81.8 & \multirow{2}{*}{$\begin{array}{l}x^{2}: \\
p=0.048\end{array}$} \\
\hline yes & 34 & 33.0 & 10 & 18.2 & \\
\hline \multicolumn{5}{|c|}{ Assistance required to complete the questionnaire } & \\
\hline No & 65 & 63.1 & 54 & 98.2 & \multirow{2}{*}{$\begin{array}{l}x^{2}: \\
p<0.001\end{array}$} \\
\hline Yes & 38 & 36.9 & 1 & 1.8 & \\
\hline
\end{tabular}

1. Starrost U (2006) Bogenhausener Dysphagiescore (BODS). Schluckstörungen: Diagnostik und Rehabilitation, 3rd edn. Urban \& Fischer, München, Jena

Table 2 Construct validity of G-SWAL-QOL and MDADI-D ( $\mathrm{n}=103$ dysphagic subjects)

\begin{tabular}{|c|c|c|c|c|c|}
\hline & \multicolumn{5}{|c|}{ M.D Anderson Dysphagia Inventory } \\
\hline G-SWAL-QOL & $\begin{array}{l}\text { Total } \\
\text { Score }\end{array}$ & Global & Emotional & Functional & Physical \\
\hline G-SWAL-QOL total $^{a}$ & $0.90^{\star *}$ & $0.76^{\star \star}$ & $0.84^{\star \star}$ & $0.82^{\star *}$ & $0.78^{\star \star}$ \\
\hline Symptoms & $0.69^{\star *}$ & $0.53^{\star \star}$ & $0.61^{\star *}$ & $0.58^{\star \star}$ & $0.68^{\star \star}$ \\
\hline
\end{tabular}




\begin{tabular}{|c|c|c|c|c|c|}
\hline Burden & $0.70^{\star \star}$ & $0.64^{\star \star}$ & $0.62^{\star \star}$ & $0.59^{\star *}$ & $0.64^{\star \star}$ \\
\hline Eating Desire & $0.59^{\star \star}$ & $0.47^{\star *}$ & $0.54^{\star \star}$ & $0.54^{\star \star}$ & $0.52^{\star \star}$ \\
\hline Eating Duration & $0.63^{\star \star}$ & $0.36^{\star}$ & $0.51^{\star *}$ & $0.52^{\star \star}$ & $0.67^{\star \star}$ \\
\hline Food Selection & $0.76^{\star \star}$ & $0.65^{\star \star}$ & $0.65^{\star \star}$ & $0.69^{\star \star}$ & $0.68^{\star \star}$ \\
\hline Communication & 0.20 & 0.06 & 0.21 & 0.19 & 0.16 \\
\hline Fear of Eating & $0.54^{\star *}$ & $0.48^{\star *}$ & $0.53^{\star *}$ & $0.43^{\star *}$ & $0.52^{\star \star}$ \\
\hline Mental Health & $0.79^{\star \star}$ & $0.65^{\star \star}$ & $0.72^{\star \star}$ & $0.66^{\star \star}$ & $0.73^{\star \star}$ \\
\hline Social Functioning & $0.84^{\star \star}$ & $0.69^{\star *}$ & $0.83^{\star \star}$ & $0.88^{\star \star}$ & $0.67^{\star \star}$ \\
\hline Fatigue & 0.32 & $0.44^{\star \star}$ & $0.36^{\star}$ & 0.31 & 0.21 \\
\hline Sleep & 0.28 & $0.35^{\star}$ & 0.29 & 0.27 & 0.19 \\
\hline
\end{tabular}

a Symptoms score is not included

Shown are the Spearman-Rho values. The Bonferroni-corrected threshold for statistical significance was set at: $0.05 / 60=0.00083\left({ }^{*}\right) ; 0.001 / 60=0.000017\left({ }^{* *}\right)$. Significant values are printed in bold.

Table 3 Construct validity of G-SWAL-QOL and SF-36 ( $\mathrm{n}=103$ dysphagic subjects)

\begin{tabular}{|c|c|c|c|c|c|c|c|c|}
\hline \multirow[b]{2}{*}{ G-SWAL-QOL } & \multicolumn{8}{|c|}{ Short-Form 36} \\
\hline & $\begin{array}{l}\text { Physical } \\
\text { Functioning }\end{array}$ & \begin{tabular}{|l|} 
Role \\
Physical
\end{tabular} & $\begin{array}{l}\text { Bodily } \\
\text { Pain }\end{array}$ & $\begin{array}{l}\text { General } \\
\text { Health }\end{array}$ & Vitality & \begin{tabular}{|l|} 
Social \\
Functioning
\end{tabular} & $\begin{array}{l}\text { Role } \\
\text { Emotional }\end{array}$ & $\begin{array}{l}\text { Mental } \\
\text { Health }\end{array}$ \\
\hline Symptoms & 0.03 & 0.32 & 0.16 & 0.24 & 0.24 & 0.27 & 0.15 & 0.19 \\
\hline Burden & -0.02 & 0.28 & $0.38^{\star}$ & 0.24 & 0.27 & 0.29 & 0.21 & 0.34 \\
\hline Eating Desire & 0.00 & 0.23 & 0.17 & 0.13 & 0.25 & 0.13 & 0.13 & 0.30 \\
\hline Eating Duration & 0.19 & 0.26 & 0.15 & 0.30 & 0.27 & 0.10 & 0.06 & 0.14 \\
\hline Food Selection & 0.02 & 0.31 & 0.30 & 0.20 & $0.36^{\star}$ & 0.28 & 0.25 & 0.33 \\
\hline Communication & 0.32 & 0.31 & 0.02 & 0.10 & 0.15 & -0.03 & -0.12 & -0.03 \\
\hline Fear of Eating & 0.28 & 0.13 & 0.06 & 0.32 & $0.39^{*}$ & 0.24 & 0.21 & 0.30 \\
\hline Mental Health & -0.02 & 0.23 & 0.23 & 0.31 & $0.41^{*}$ & 0.21 & 0.16 & $0.37^{*}$ \\
\hline Social Functioning & 0.09 & 0.27 & 0.26 & 0.26 & $0.35^{\star}$ & $0.43^{\star \star}$ & 0.26 & $0.37^{*}$ \\
\hline Fatigue & $0.37^{\star}$ & $0.36^{*}$ & 0.33 & $0.37^{\star}$ & $0.63^{\star \star}$ & $0.45^{\star \star}$ & 0.21 & $0.41^{*}$ \\
\hline Sleep & 0.03 & 0.27 & 0.18 & 0.26 & $0.38^{\star}$ & $0.34^{*}$ & 0.22 & $0.44^{\star \star}$ \\
\hline
\end{tabular}

Shown are the Spearman-Rho values.

The Bonferroni-corrected threshold for statistical significance was set at $0.05 / 88=0.00057\left({ }^{*}\right)$;

$\left.0.001 / 88=0.000011{ }^{* *}\right)$ Significant values are printed in bold.

Table 4 Differences between dysphagic and control group on G-SWAL-QOL (Known-groups validity)

\begin{tabular}{|l|l|l|l|l|l|l|l|}
\hline & \multicolumn{2}{|l|}{ patients $(\mathrm{n}=103)$} & \multicolumn{2}{l|}{ controls $(\mathrm{n}=55)$} & \\
\hline G-SWAL-QOL & mean & SD & mean & SD & $\begin{array}{l}\text { mean } \\
\text { difference }\end{array}$ & $\begin{array}{l}\text { Sig. (two tailed) } \\
\text { Mann-Whitney- } \\
\text { U-Test }\end{array}$ & $\begin{array}{l}\text { effect } \\
\text { size }(r)\end{array}$ \\
\hline
\end{tabular}


German SWAL-QOL: validation and psychometric properties

\begin{tabular}{|l|l|l|l|l|l|l|l|}
\hline G-SWAL-QOL total $^{\mathrm{a}}$ & 56.5 & 19.1 & 94.9 & 4.6 & -38.4 & $<0.000001$ & 0.80 \\
\hline Symptoms & 60.9 & 14.9 & 95.4 & 7.2 & -34.5 & $<0.000001$ & 0.80 \\
\hline Burden & 49.9 & 30.8 & 99.8 & 1.7 & -49.9 & $<0.000001$ & 0.79 \\
\hline Eating Desire & 66.8 & 26.6 & 95.9 & 11.2 & -29.1 & $<0.000001$ & 0.60 \\
\hline Eating Duration & 43.2 & 34.2 & 97.5 & 9.1 & -54.3 & $<0.000001$ & 0.71 \\
\hline Food Selection & 68.7 & 29.4 & 98.2 & 6.6 & -29.5 & $<0.000001$ & 0.57 \\
\hline Communication & 49.0 & 26.9 & 95.9 & 10.8 & -46.9 & $<0.000001$ & 0.74 \\
\hline Fear of Eating & 59.5 & 25.1 & 98.0 & 5.9 & -38.4 & $<0.000001$ & 0.77 \\
\hline Mental Health & 55.3 & 25.4 & 99.2 & 3.9 & -43.9 & $<0.000001$ & 0.79 \\
\hline Social Functioning & 63.6 & 31.1 & 99.8 & 1.3 & -36.2 & $<0.000001$ & 0.66 \\
\hline Fatigue & 44.3 & 23.9 & 78.2 & 17.6 & -33.8 & $<0.000001$ & 0.61 \\
\hline Sleep & 53.3 & 28.8 & 77.7 & 21.6 & -24.5 & $<0.000001$ & 0.40 \\
\hline
\end{tabular}

${ }^{a}$ Symptoms score is not included

The Bonferroni-corrected threshold for statistical significance was set at $0.05 / 12=0.0042$;

$0.001 / 12=0.000083$.

Table 5: Internal consistency and test-retest reliability of G-SWAL-QOL

\begin{tabular}{|c|c|c|c|}
\hline \multirow[b]{2}{*}{ G-SWAL-QOL } & \multirow{2}{*}{$\begin{array}{l}\begin{array}{l}\text { Internal } \\
\text { consistency }\end{array} \\
\text { Cronbach's } \alpha\end{array}$} & \multicolumn{2}{|c|}{ Test-retest reliability $^{\mathrm{C}}$} \\
\hline & & Spearman's rho & $\begin{array}{l}\text { Intraclass } \\
\text { correlations }\end{array}$ \\
\hline 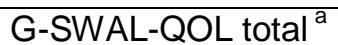 & 0.94 & $0.92^{\star *}$ & $0.96^{\star *}$ \\
\hline Symptoms & 0.80 & $0.92^{* *}$ & $0.92^{* \star}$ \\
\hline Burden & 0.90 & $0.87^{\star \star}$ & $0.93^{\star \star}$ \\
\hline Eating Desire & 0.69 & $0.72^{\star}$ & $0.90^{\star *}$ \\
\hline Eating Duration & 0.78 & $0.95^{\star *}$ & $0.98^{* *}$ \\
\hline Food Selection & 0.71 & $0.94^{\star *}$ & $0.96^{\star \star}$ \\
\hline Communication & 0.73 & $0.70^{*}$ & $0.85^{\star *}$ \\
\hline Fear of Eating & 0.78 & $0.86^{\star *}$ & $0.92^{\star *}$ \\
\hline Mental Health & 0.90 & $0.92^{\star \star}$ & $0.92^{\star \star}$ \\
\hline Social Functioning & 0.93 & $0.87^{* *}$ & $0.96^{* *}$ \\
\hline Fatigue & 0.85 & $0.68^{*}$ & $0.84^{*}$ \\
\hline Sleep & 0.73 & $0.69^{*}$ & $0.81^{*}$ \\
\hline
\end{tabular}

Symptoms score is not included

${ }^{b}$ Internal consistency, $\mathrm{n}=103$ dysphagic subjects

${ }^{c}$ Test-retest reliability, $\mathrm{n}=20$ dysphagic subjects, average test-retest interval $=14$ days

${ }^{d}$ Two-way mixed effects model, absolute agreement

The Bonferroni-corrected threshold for statistical significance was set at $0.05 / 12=0.0042\left({ }^{*}\right)$;

$0.001 / 12=0.000083\left({ }^{* \star}\right)$

Table 6 Normative data G-SWAL-QOL in 103 dysphagic subjects

\begin{tabular}{|c|c|c|c|c|c|c|c|}
\hline G-SWAL-QOL & Items & Range & Mean & Median & SD & $\begin{array}{l}\% \text { floor } \\
\text { effects }\end{array}$ & $\begin{array}{l}\text { \% ceiling } \\
\text { effects }\end{array}$ \\
\hline G-SWAL-QOL total ${ }^{a}$ & 30 & $8-95$ & 56.5 & 57.5 & 19.1 & 0 & 0 \\
\hline Symptoms & 14 & $14-89$ & 60.9 & 60.7 & 14.9 & 0 & 0 \\
\hline
\end{tabular}


German SWAL-QOL: validation and psychometric properties

\begin{tabular}{|l|l|l|l|l|l|l|l|}
\hline Burden & 2 & $0-100$ & 49.9 & 50.0 & 30.8 & 13.6 & 6.8 \\
\hline Eating Desire & 3 & $8-100$ & 66.8 & 66.7 & 26.6 & 0 & 19.4 \\
\hline Eating Duration & 2 & $0-100$ & 43.2 & 37.5 & 34.2 & 15.5 & 12.6 \\
\hline Food Selection & 2 & $0-100$ & 68.7 & 75.0 & 29.4 & 1.9 & 30.1 \\
\hline Communication & 2 & $0-100$ & 49.0 & 50.0 & 26.9 & 10.7 & 6.8 \\
\hline Fear of Eating & 4 & $0-100$ & 59.5 & 62.5 & 25.1 & 2.9 & 4.9 \\
\hline Mental Health & 5 & $0-100$ & 55.3 & 55.0 & 25.4 & 1.9 & 4.9 \\
\hline Social Functioning & 5 & $0-100$ & 63.6 & 70.0 & 31.1 & 1.9 & 24.3 \\
\hline Fatigue & 3 & $0-100$ & 44.3 & 50.0 & 23.9 & 6.8 & 1.9 \\
\hline Sleep & 2 & $0-100$ & 53.3 & 50.0 & 28.8 & 7.8 & 12.6 \\
\hline
\end{tabular}

${ }^{a}$ Symptoms score is not included.

Validation and Psychometric Properties of the German Version of the SWAL-QOL

Journal: Dysphagia 
Supplementary Material 1: Subject characteristics of the comprehensibility testing of the preliminary German SWAL-QOL version (step 5 of the translation process)

\begin{tabular}{|c|c|c|c|c|}
\hline Characteristic & \multicolumn{2}{|c|}{ Study group $(n=45)$} & \multicolumn{2}{|c|}{$\begin{array}{l}\text { Additional study group for } \\
\text { further testing of item \#29 } \\
(n=22)\end{array}$} \\
\hline \multicolumn{5}{|l|}{ Age (years) } \\
\hline mean (SD) & $62.9(12,3)$ & & $57.6(14.6)$ & \\
\hline median & 65.0 & & 61.5 & \\
\hline \multirow[t]{2}{*}{ range } & $32-85$ & & $25-79$ & \\
\hline & number & $\%$ & number & $\%$ \\
\hline \multicolumn{5}{|l|}{ Gender } \\
\hline Male & 25 & 55.6 & 15 & 68.2 \\
\hline Female & 20 & 44.4 & 7 & 31.8 \\
\hline \multicolumn{5}{|l|}{ Etiology } \\
\hline head and neck cancer & 16 & 35.6 & 9 & 40.9 \\
\hline vascular disease (stroke) & 6 & 13.3 & 2 & 9.1 \\
\hline Parkinson's Disease & 9 & 20.0 & 4 & 18.2 \\
\hline other neurodegenerative diseases & 6 & 13.3 & 2 & 9.1 \\
\hline other neurologic diseases & 3 & 6.7 & 3 & 13.6 \\
\hline other non-neurological dysphagia & 5 & 11.1 & 2 & 9.1 \\
\hline
\end{tabular}

A group of dysphagic patients $(n=45)$ tested the preliminary German SWALQOL version for comprehensibility of phrasing and language. After item \#29 was revealed to be difficult to understand, it was reconsidered and modified by the expert committee. An additional group of dysphagic patients $(n=22$ subjects) was recruited to evaluate the comprehensibility of the new translated item \#29. 
Supplementary Material 2: Construct validity of G-SWAL-QOL and the SF36 component scores

\begin{tabular}{|c|c|c|}
\hline \multirow[b]{2}{*}{ G-SWAL-QOL } & \multicolumn{2}{|c|}{ Short-Form 36} \\
\hline & PCS & MCS \\
\hline G-SWAL-QOL total ${ }^{a}$ & 0.25 & $0.46^{\star \star}$ \\
\hline Symptoms & 0.14 & 0.25 \\
\hline Burden & 0.14 & $0.33^{*}$ \\
\hline Eating Desire & 0.08 & 0.24 \\
\hline Eating Duration & 0.27 & 0.12 \\
\hline Food Selection & 0.14 & $0.35^{\star}$ \\
\hline Communication & $0.32^{\star}$ & -0.10 \\
\hline Fear of Eating & 0.21 & $0.31^{*}$ \\
\hline Mental Health & 0.11 & $0.33^{*}$ \\
\hline Social Functioning & 0.13 & $0.43^{\star \star}$ \\
\hline Fatigue & $0.42^{\star \star}$ & $0.43^{\star \star}$ \\
\hline Sleep & 0.11 & $0.44^{\star \star}$ \\
\hline
\end{tabular}

Symptoms score is not included

Shown are the Spearman-Rho values $\left(r_{\mathrm{s}}\right), \mathrm{n}=103$ dysphagic subjects.

The Bonferroni-corrected threshold for statistical significance was set at 0.05/24=0.002 $\left({ }^{*}\right)$;

$\left.0.001 / 24=0.00004{ }^{* *}\right)$. Significant values are printed in bold.

The SF-36 Mental Health Component Score (MCS) shows moderate correlations $\left(r_{\mathrm{s}} 0.31-0.44\right)$ with several of the G-SWAL-QOL subscales (Burden, Food Selection, Fear of Eating, Mental Health, Social Functioning, Fatigue and Sleep) as well as with the G-SWAL-QOL total $\left(r_{\mathrm{s}}=0.46\right)$. No significant correlations were found between the MCS and the G-SWAL-QOL subscales Eating Desire, Eating Duration, Communication and the Symptoms scale. These results correspond with data from the correlation analysis of the GSWAL-QOL and the SF-36 domains (see Table 3) and support both convergent and discriminant validity of the G-SWAL-QOL (see Results, main text).

The SF-36 Physical Health Component Score (PCS) did not significantly correlate with any of the G-SWAL-QOL subscales, except the Communication and the Fatigue subscales ( $r_{\mathrm{s}}=0.32$ and 0.42 , respectively). These results can be taken as an additional indicator for the discriminant validity of the G-SWALQOL given that general physical health (as captured by the PCS) and 
German SWAL-QOL: validation and psychometric properties

dysphagia-specific quality of life (as captured by the G-SWAL-QOL) represent two largely different constructs [1]. 


\section{Supplementary Material 3: Principal Component Analysis (PCA) of subscales of the G-SWAL-QOL}

Rationale. Principal Component Analysis (PCA) examines how many constructs or latent variables underlie a set of items. The purpose is to explain a maximal amount of total variance within the least possible number of explanatory constructs [2]. We analyzed if the subscales of the G-SWAL-QOL present at least two distinctive constructs: dysphagia-specific QOL and generic QOL. This hypothesis is based on the observation that two G-SWAL-QOL subscales seem to capture generic, non-dysphagia items, namely the subscales Sleep and Fatigue.

Methods. We first tested whether our data were of sufficient quality to perform a PCA, calculating Bartlett's Test of Sphericity and the Kaiser-Meyer-Olkin Measure of Sampling Adequacy (KMO) [3]. A PCA was then performed. The Kaiser criterion (eigenvalues-exceeding-one rule) and the scree-plot were used to determine the number of salient underlying factors [2]. To facilitate interpretation, orthogonal (Varimax) and oblique (Oblimin direct) rotation were used. However, oblique rotation is recommended because some correlations exceeded 0.32 in the factor correlation matrix $[2,4]$.

Results. Bartlett's Test of Sphericity was statistically significant $(p<0.0001)$ and the $\mathrm{KMO}$ value was 0.857 (greater than the threshold of 0.6 ). This indicates that both, the correlation matrix and the sample size were sufficient for PCA [3]. PCA extracted three distinct factors with an eigenvalue greater than one. The first factor (eigenvalue $=4.52$, explaining $45.2 \%$ of the total variance) covers the subscales Food Selection, Eating Desire, Burden, Social Functioning, Eating Duration, Mental Health and Fear of Eating and was set as the dysphagia-specific QOL factor. The second factor (eigenvalue $=1.22$, explaining $12.2 \%$ of the total variance) covers the subscales Sleep and Fatigue and was set as a dysphagia-unrelated, generic QOL factor. The third factor (eigenvalue 1.04 , explaining $10.4 \%$ of the total variance) consists of the Communication subscale. After orthogonal and oblique rotation the factor structure remained mainly unchanged. Only the Fear of Eating subscale loaded higher on the second factor than on the first factor, especially in the component 
matrix after orthogonal rotation. In the pattern matrix, after oblique rotation the Fear of Eating subscale could not be assigned to any of the three extracted factors. See Table.

Factor loadings at subscale level of the G-SWAL-QOL

\begin{tabular}{|c|c|c|c|c|c|c|c|c|c|}
\hline \multirow[t]{3}{*}{ G-SWAL-QOL } & \multicolumn{3}{|c|}{$\begin{array}{l}\text { Component matrix } \\
\text { without rotation }\end{array}$} & \multicolumn{3}{|c|}{$\begin{array}{l}\text { Pattern matrix after } \\
\text { oblique rotation } \\
\text { (oblimin direct) }\end{array}$} & \multicolumn{3}{|c|}{$\begin{array}{l}\text { Component matrix } \\
\text { after orthogonal } \\
\text { rotation (varimax) }\end{array}$} \\
\hline & \multicolumn{9}{|c|}{ Components/factors } \\
\hline & 1 & 2 & 3 & 1 & 2 & 3 & 1 & 2 & 3 \\
\hline Food Selection & 0.80 & -0.15 & $-0,24$ & 0.86 & 0,03 & -0.11 & 0.83 & 0,19 & -0.03 \\
\hline Eating Desire & 0.68 & -0.33 & $-0,23$ & 0.84 & $-0,18$ & -0.05 & 0.79 & $-0,02$ & 0.02 \\
\hline Burden & 0.83 & 0.03 & $-0,19$ & 0.76 & 0,23 & -0.12 & 0.76 & 0,37 & -0.04 \\
\hline Social Functioning & 0.83 & -0.08 & $-0,05$ & 0.75 & 0,16 & 0.06 & 0.76 & 0,31 & 0.12 \\
\hline Eating Duration & 0.65 & -0.44 & 0,11 & 0.70 & $-0,18$ & 0.31 & 0.69 & $-0,04$ & 0.37 \\
\hline Mental Health & 0.85 & 0.07 & $-0,05$ & 0.68 & 0,32 & 0.02 & 0.71 & 0,45 & 0.08 \\
\hline Fear of Eating & 0.68 & 0.19 & 0,31 & 0.31 & 0,50 & 0.31 & 0.41 & 0,56 & 0.34 \\
\hline Communication & 0.21 & -0.33 & 0,86 & -0.08 & 0,02 & 0.96 & 0.04 & 0,03 & 0.95 \\
\hline Sleep & 0.43 & 0.64 & 0,17 & -0.06 & 0,81 & 0.00 & 0.07 & 0,79 & 0.00 \\
\hline Fatigue & 0.48 & 0.58 & 0,10 & 0.05 & 0,74 & -0.04 & 0.15 & 0,74 & -0.03 \\
\hline
\end{tabular}

$\mathrm{n}=103$ dysphagic subjects. Values $>0.5$ are printed in bold.

Oblimin direct rotation converged in six iterations. Varimax rotation converged in five iterations

\section{Comparison of the factor structure of the G-SWAL-QOL and the original SWAL-QOL.}

The factor structure of the G-SWAL-QOL is largely comparable (albeit not fully identical) to the factor structure of the original SWAL-QOL. In the original SWAL-QOL two factors were extracted: Factor 1 "dysphagia-specific QOL" (Food Selection, Burden, Mental Health, Social Functioning, Fear of Eating, Eating Duration, Eating Desire, Communication) and Factor 2 "generic QOL" (Sleep and Fatigue) [5].

In our analysis of the G-SWAL-QOL, the Communication subscale represents a third, distinct factor. This finding is corroborated by a similar result from a previous PCA analysis of the Chinese version of the SWAL-QOL, where the Communication subscale could neither be grouped under the dysphagiaspecific QOL factor nor under the generic QOL factor [6]. Also in the original 
SWAL-QOL the factor loading of the Communication subscale was only marginal for the dysphagia-specific QOL factor (0.54) [5]. In sum, the Communication subscale rather presents a distinct, third factor. This factor seems to capture communication-related QOL. This notion is supported when reviewing the wording of the two items of the Communication subscale, which are clearly not dysphagia-related but communication related. The wording is: (i) "People have a hard time understanding me.", (ii) "It's been difficult for me to speak clearly".

Furthermore, the Fear of Eating subscale could not be categorized under the dysphagia-specific QOL factor after rotation. We speculate that this result might occur due to the fact that item \#29 - which is part of the Fear of Eating subscale - obtained only relatively poor comprehensibility in comprehensibity testing. If a substantial share of patients did not understand this item, they could have replied randomly. Thus, as stated in the Discussion section in the main text, this subscale should be considered with caution. Further studies are warranted to examine whether the Fear of Eating subscale might be grouped under the dysphagia-specific factor if further modifying or omitting item \#29 (for further discussion of item \#29, see main text) 


\section{Supplementary Material 4: G-SWAL-QOL results for dysphagic patients stratified according to food texture of individual eating behavior}

\begin{tabular}{|c|c|c|c|c|c|c|}
\hline \multirow[b]{2}{*}{ G-SWAL-QOL } & \multicolumn{2}{|c|}{$\begin{array}{l}\text { Unmodified diet } \\
(n=56) \text { vs soft \& } \\
\text { pureed diet }(n=29)\end{array}$} & \multicolumn{2}{|c|}{$\begin{array}{l}\text { Unmodified diet } \\
(n=56) \text { vs tube fed } \\
(n=18)\end{array}$} & \multicolumn{2}{|c|}{$\begin{array}{l}\text { Soft \& pureed diet } \\
(n=29) \text { vs tube } \\
\text { fed }(n=18)\end{array}$} \\
\hline & $\begin{array}{l}\text { Korr. Sig. } \\
\text { (post-hoc) }\end{array}$ & $\begin{array}{l}\text { Effect } \\
\text { size }(r)\end{array}$ & $\begin{array}{l}\text { Korr. Sig. } \\
\text { (post-hoc) }\end{array}$ & $\begin{array}{l}\text { Effect } \\
\text { size }(r)\end{array}$ & $\begin{array}{l}\text { Korr. Sig. } \\
\text { (post hoc) }\end{array}$ & \begin{tabular}{|l} 
Effect \\
size $(r)$
\end{tabular} \\
\hline G-SWAL-QOL total $^{\mathrm{a}}$ & $<0.00001^{* *}$ & 0.68 & $0.0005^{\star}$ & 0.44 & 0.505 & - \\
\hline Symptoms & $0.0004^{*}$ & 0.41 & $0.0003^{*}$ & 0.45 & 1.0 & \\
\hline Burden & $<0.00001^{* *}$ & 0.54 & $0.0002^{*}$ & 0.47 & 1.0 & \\
\hline Eating Desire & $<0.00001^{* *}$ & 0.51 & 0.058 & - & 0.424 & \\
\hline Eating Duration & $<0.00001^{* *}$ & 0.54 & 0.196 & - & 0.095 & \\
\hline Food Selection & $<0.00001^{\star *}$ & 0.57 & $0.001^{*}$ & 0.42 & 1.0 & \\
\hline Communication & \multicolumn{6}{|c|}{ no significant differences between groups (Kruskall-Wallis) } \\
\hline Fear of Eating & \multicolumn{6}{|c|}{ no significant differences between groups after Bonferroni correction } \\
\hline Mental Health & $<0.00001^{\star *}$ & 0.58 & $0.0002^{*}$ & 0.47 & 1.0 & - \\
\hline Social Functioning & $<0.00001^{* *}$ & 0.62 & 0.002 & 0.40 & 0.594 & {[} \\
\hline Fatigue & \multicolumn{6}{|c|}{ no significant differences between groups after Bonferroni correction } \\
\hline Sleep & \multicolumn{6}{|c|}{ no significant differences between groups (Kruskall-Wallis) } \\
\hline
\end{tabular}

Symptoms score is not included

The Bonferroni-corrected threshold for statistical significance was set at: 0.05/12=0.0042 $\left(^{*}\right)$;

$\left.0.001 / 12=0.000083{ }^{(* *}\right)$

The dysphagia patient group was classified per food texture which individuals could swallow. The categories "soft diet" and "pureed diet" and the categories "mainly tube-fed" and "completely tube-fed" were combined as these categories show large overlap and are often hard to distinguish in practice. Within-group differences were compared using Kruskal-Wallis-Test. When the Kruskal-Wallistest yielded a significant effect $(p<0.05)$, post-hoc analysis was performed using a Dunn-Bonferroni-Test, and significance was Bonferroni-corrected for multiple comparisons.

Significant differences were observed in all subscales between patients on an unmodified diet and patients on a soft or pureed diet, except the subscales Communication, Fear of Eating, Fatigue and Sleep.

In contrast, less subscales showed significant differences between patients on an unmodified diet and patients who are mainly or completely tube-fed. This might be because some items of the SWAL-QOL address only oral feeders, and are hard to answer for patients who are only tube-fed (e.g. item \#4 "It takes me longer to eat than other people."). This assumption is supported by our finding 
German SWAL-QOL: validation and psychometric properties

that tube-fed patients had significantly higher levels of missing items (see Results, main text). McHorney el al and Rinkel et al. found a similar limitation in their studies $[5,7]$. 
German SWAL-QOL: validation and psychometric properties 
Supplementary Material 5: G-SWAL-QOL, MDADI-D and SF-36 results for dysphagia patient group stratified according to food texture of individual eating behavior

\begin{tabular}{|c|c|c|c|c|c|c|}
\hline & \multicolumn{2}{|c|}{$\begin{array}{l}\text { Unmodified diet } \\
(n=56) \text { vs soft \& } \\
\text { pureed diet }(n=29)\end{array}$} & \multicolumn{2}{|c|}{$\begin{array}{l}\text { Unmodified diet } \\
(n=56) \text { vs tube fed } \\
(n=18)\end{array}$} & \multicolumn{2}{|c|}{$\begin{array}{l}\text { Soft \& pureed diet } \\
(n=29) \text { vs tube } \\
\text { fed }(n=18)\end{array}$} \\
\hline & $\begin{array}{l}\text { Korr. Sig. } \\
\text { (post-hoc) }\end{array}$ & $\begin{array}{l}\text { Effect } \\
\text { size }(r)\end{array}$ & $\begin{array}{l}\text { Korr. Sig. } \\
\text { (post-hoc) }\end{array}$ & $\begin{array}{l}\text { Effect } \\
\text { size }(r)\end{array}$ & $\begin{array}{l}\text { Korr. Sig. } \\
\text { (post hoc) }\end{array}$ & $\begin{array}{l}\text { Effect } \\
\text { size }(r)\end{array}$ \\
\hline G-SWAL-QOL total $^{\mathrm{a}}$ & $<0.0001^{* *}$ & 0.68 & $0.0005^{\star}$ & 0.44 & 0.505 & \\
\hline MDADI-D total & $<0.0001^{* *}$ & 0.67 & $<0.0001^{* *}$ & 0.48 & 0.998 & \\
\hline SF-36 PCS & \multicolumn{6}{|c|}{ no significant differences between groups (Kruskall-Wallis, $p=0.354$ ) } \\
\hline SF-36 MCS & \multicolumn{6}{|c|}{ no significant differences between groups (Kruskall-Wallis, $p=0.079$ ) } \\
\hline
\end{tabular}

${ }^{a}$ Symptoms score is not included

The Bonferroni-corrected threshold for statistical significance was set at: $0.05 / 4=0.0125\left({ }^{*}\right)$; $\left.0.001 / 4=0.00025{ }^{* *}\right)$

To analyze whether G-SWAL-QOL, MDADI-D and SF-36 really capture dysphagia-related impairment in a similar fashion, we compared their ability to differentiate between patients without food limitations and patients with food limitations within the dysphagia patient group. To this end, the dysphagic patient group was classified according to food texture of individual eating behavior as described in Supplementary Material 4 (unmodified diet, soft \& pureed diet, tube-fed). The within-group differences were compared using Kruskal-WallisTest. When the Kruskal-Wallis-test yielded a significant effect $(p<0.05)$, posthoc analysis was performed using a Dunn-Bonferroni-Test, and the results were Bonferroni-corrected for multiple comparisons.

The G-SWAL-QOL and the MDADI-D showed highly significant differences between patients with an unmodified diet versus patients with food limitations. In contrast, the SF-36 component scores did not differentiate between groups.

This suggests that the G-SWAL-QOL and the MDADI-D capture dysphagiarelated QOL impairments more closely, while the SF-36 does not capture such a specific construct. It rather seems to be designed to capture the generic construct of more general health related QOL. 
E. Kraus et al.: German SWAL-QOL: validation and psychometric properties

\section{References}

1. Wilson IB, Cleary PD (1995) Linking clinical variables with health-related quality of life: a conceptual model of patient outcomes. Jama 273 (1):59-65

2. DeVellis RF (2012) Scale development: theory and applications. 3rd edn. Sage publications, Los Angeles

3. Dziuban CD, Shirkey EC (1974) When is a correlation matrix appropriate for factor analysis? Some decision rules. Psychological bulletin 81 (6):358

4. Tabachnick B, Fidell L (2007) Using Multivariate Statistics., 5th edn.(Pearson: Boston, MA.). 646

5. McHorney CA, Robbins J, Lomax K, Rosenbek JC, Chignell K, Kramer AE, Bricker DE (2002) The SWAL-QOL and SWAL-CARE outcomes tool for oropharyngeal dysphagia in adults: III. Documentation of reliability and validity. Dysphagia 17 (2):97-114

6. Lam PM, Lai CKY (2011) The validation of the Chinese version of the Swallow Quality-of-Life Questionnaire (SWAL-QOL) using exploratory and confirmatory factor analysis. Dysphagia 26 (2):117-124

7. Rinkel RN, Verdonck-de Leeuw IM, Langendijk JA, van Reij EJ, Aaronson NK, Leemans CR (2009) The psychometric and clinical validity of the SWAL-QOL questionnaire in evaluating swallowing problems experienced by patients with oral and oropharyngeal cancer. Oral oncology 45 (8):e67-e71 